\title{
Modelling Of Wind Turbine Magnet for Magnetic Abrasive Finishing and Magnetic Field Assisted Abrasive Flow Machining Process
}

\author{
Anant Bhardwaj, Krovvidi Srinivas* and Rajiv Chaudhary \\ Department of Mechanical Engineering, Delhi Technological University, Shahabad Daulatpur, Main Bawana Road Delhi, India \\ * Corresponding Author : srinivaskrovvidi@dtu.ac.in
}

\begin{abstract}
Magnetic Abrasive Finishing is a significant process for finishing up to the micro-level. However, with the advancement of technology and hybrids like Viscoelastic magnetic abrasive Finishing and Magnetic abrasive Flow machining, it has become a nano finishing process. To improve the finishing process, the researchers have made a Model and tested the feasibility of the wind turbine magnet in Finishing. The Maxwell simulations were done for the cylindrical Specimen of Brass, Steel Aluminum. The simulations results were in accordance with the fact that the proposed wind turbine magnet may be used for the simulations.
\end{abstract}

Keywords: Magnetic field assisted abrasive flow machining; Viscoelastic magnetic abrasive finishing.

\section{INTRODUCTION}

The magnet used in the wind turbine is powerful .The research on magnetic abrasive Finishing is mostly confined to the electromagnet or the particular shape magnet. The research's main objective is to open a new area in the finishing process by magnet where wind magnets play a vital role. Magnetic abrasive Finishing is an effective process. Many researchers have worked on it and (Wang et al. 2004) used a magnetic abrasive finishing process on the tube's inner surface, which produces a highly finished inner surface of the critical application tube. The researchers calculated the stress on the abrasive grain and are analyzed it along with the grinding mechanism. The researchers used the magnetic abrasive Machining process for calculating the Finishing on the austenitic stainless steel tubing. After the successful experimentation, the researchers observed that a big size magnetic abrasive particle has a more significant normal force than smaller particles. Also, the normal force is proportional to the exciting current. The normal force is the essential factor for deciding the MRR compared with other factors like exciting current, grid size etc. (Rohit et al. 2017) developed a new magnetic abrasive. The researcher developed the magnetic Particle by mixing abrasive, ferromagnetic powder and a particular type of adhesive bonding. For comparing the created magnetic Particle, the researchers made another two particles, one by sintering and the other by simple mixing techniques. When the researcher compared magnetic abrasive particles by using Brass as the workpiece. After reaching the results, it is found that the magnetic Particle made by mixing silicon carbide and abrasive yields 18 per cent of the surface improvement. In contrast, the abrasive made by adhesive bond iron-sic the percentage improvement is 42 per cent, and for the Particle made by sintered iron-Sic, the surface roughness observed was 49 per cent. (Kang et al. 2017) Summarized the machining process and the magnetic particles and reviewed their machining process and the abrasive magnetic finishing processes. The researcher concluded that Sintered Magnetic Abrasive have greater life compared to the mixed MAPs. Moreover, Sintered Magnetic Abrasive Particles has an edge over mixed merely MAPs when MRR is taken into account. Also, 
the surface finish for the Sintered magnetic abrasive is more than that of the sample size. The researchers' other key observation was the wet abrasive give better finishing results compared to the dry abrasive. (Muhammad et al. 2016) Conducted there to experiment on the tube's inner surface finish. The researcher used the electrolysis method combined with magnetic abrasive Finishing, making it suitable for effective machining. The researcher claimed that the process of Electrolysis is effective for the machining process. Still, the main disadvantage is the formation of the pit residual and the formation of oxidation level on the surface, resulting in the degradation of the character's quality. However, magnetic abrasive Finishing over the surface is an effective method of removing the oxidation layer over the surface and effectively finishing. (Srikande et. al. 2018) Compared the magnetic abrasive flow machining with the conventional abrasive flow machining process to Perform the Finishing operations on dog clutch with internal splines. The researcher compared the finishing process by taking five parameters: Machining time (per work piece), Setup Time, Surface Finish, Productivity, and accuracy. According to the researchers, the machining time for the MAFM process is 3-minute compare to the machining time of 5 minutes for the conventional one. The surface finish value obtained for the MAFM process is up to 3-5 microns, whereas, for the conventional process, it is 0.05 to 1 micron. The material removal rate for the MAFM is also high, and it went up to 0.020 to $0.030 \mathrm{~mm}$, and for the conventional machining process, it was 0.008 to $0.01 \mathrm{~mm}$. Finally, the researchers concluded that the productivity is higher for the MAFM process than the conventional AFM process. (Chen et al. 2010) Prepared a magnetic abrasive by the process of sintering and pressing. The researchers conducted experiments on the developed abrasives. They concluded that the pressing and sintering abrasive has a good finishing performance, Effective improvement in surface quality, long service life, adaptability, and improvement in the surface finish. (Judal et al. 2016) studied CMAF, which is a cylindrical Magnetic abrasive finishing process. The researchers developed the FEM model and simulated the process, and verified it by the literature present. The researchers highlighted the advantage of the cylindrical Magnetic abrasive finishing process over the Conventional Magnetic Abrasive Finishing. (Srinivas et al. 2019) studied the permanent magnet's various shape and selected four among them. The researchers model the 4 cases on the Ansys Maxwell and found that the Arc magnet shows the other magnet's best results. The distribution of magnetic field intensity over the workpiece's surface was better in this case. The value of Magnetic Field intensity was highest in this case. In another investigation, (Srinivas et.al.2019) took the arc magnet commercially available in the market and studied the magnet's effect by arranging it at a different pole. the researchers took two arc magnet types with two central angles, with one having an angle of 60 degrees and the other having an angle of 90.The research's important inferences were that the magnet's central angle is one of the crucial parameters in the finishing effect of the workpiece; among all the cases, the one with a 90-degree angle has the maximum magnetic felid intensity. In the further application, (Srinivas et al. 2019) used ANSYS Fluent and tested a viscoelastic media and computed the value of pressure and the force exerted by the viscoelastic fluid on the workpiece to be machined.(Srinivas et al. 2019) used electromagnet for the process of viscoelastic magnet abrasive finishing process and plotted a curve representing the magnetic felid variation with the current, and concluded that the magnetic felid is practically proportional to the current as it represents an approximate straight line. thus MAF is Key parameters in the field of finishing.

\section{METHODOLOGY}

The wind magnet in the market was modelled on CREO Software and tested on the ANSYS MAXWELL 16 software. The result is tested and based on aluminium, Brass and Steel; the magnet was used for this purpose. A hollow workpiece is taken and is kept inside the hollow magnet, whose outer diameter is about $36 \mathrm{~mm}$ diameter. The material of the magnet is NdFe 35 and the hollow workpiece material was taken differently. So firstly, the analysis is done on the hollow workpiece. The workpiece taken was to check the distribution, so on CREO 3.0 software, so a hollow tube of outer diameter $30 \mathrm{~mm}$ and the thickness of $5 \mathrm{~mm}$ was made of height $20 \mathrm{~mm}$ was drawn. For the magnet, the magnet's assembly is made with a collection of 8 Pieces with $36 \mathrm{~mm}$ outer diameter and $32 \mathrm{~mm}$ inner diameter. The assembly was made on the CREO 3.0 Software and a copy of the assembly is made is sent to ANSYS Maxwell through an IGES File and is open on ANSYS MAXWELL for simulations. The figure 1(a) yellow portion shows the magnet and the blue part represent the workpiece. Figure 1(b) shows the actual magnet. 


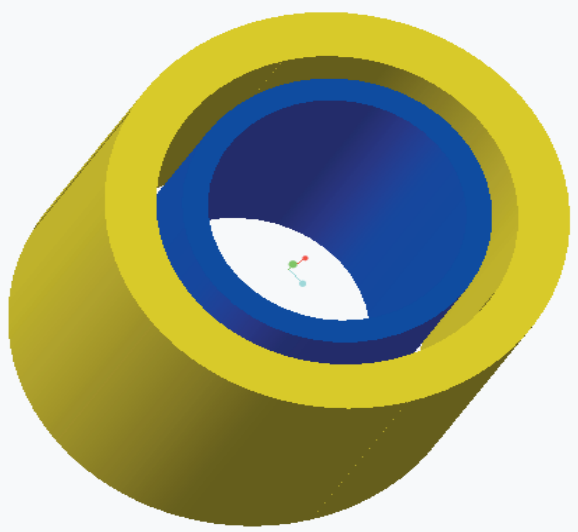

Figure 1. (a)

CREO 3.0 model for 36 diameter magnet

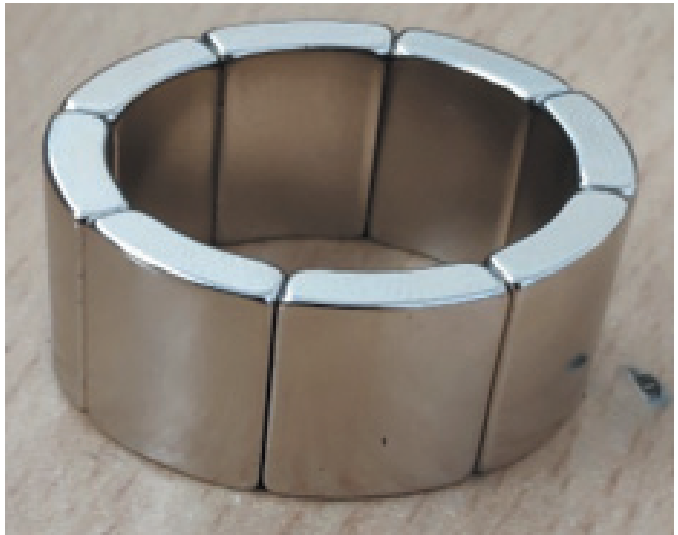

Figure 1. (b)

Actual $36 \mathrm{~mm}$ diameter magnet

\section{SIMULATIONS}

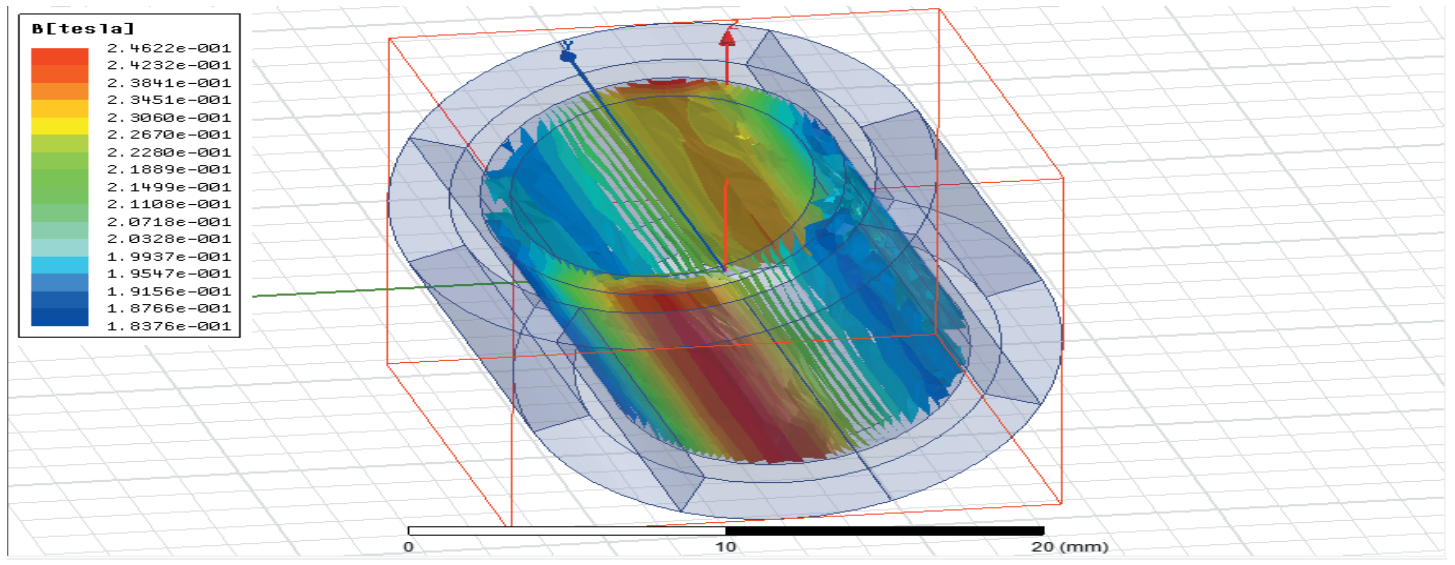

Figure 2. Magnetic Field distribution for aluminium workpiece

The above figure shows a magnet with an eight-piece of an outer diameter of $36 \mathrm{~mm}$ diameter and an inner diameter of $32 \mathrm{~mm}$.theworkpiece is made up of a hollow tube of an outer diameter of $30 \mathrm{~mm}$. A thickness of $5 \mathrm{~mm}$ was made. The material assign to the magnet is NDFE 35 and that of the workpiece is aluminium. The above figure shows the aluminium's magnetic field distribution with the maximum value of 0.2462 Tesla and the minimum value of 0.1837 Tesla. Aluminium is non-ferrous material. With this simulation, it is evident that the magnetic field's intensity on the surface would be less than the ferrous material. The result would be almost similar to Brass as they both share the same non-ferrous material property. 


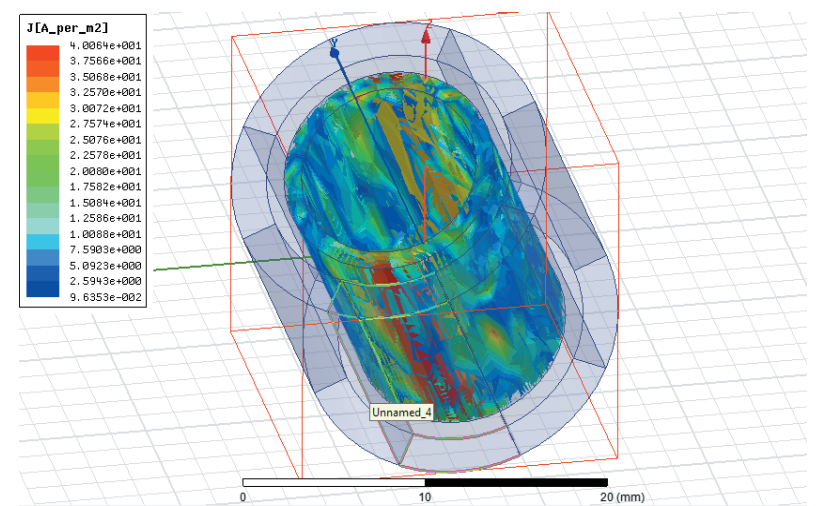

Figure 3. Current Density Distribution for aluminium work piece

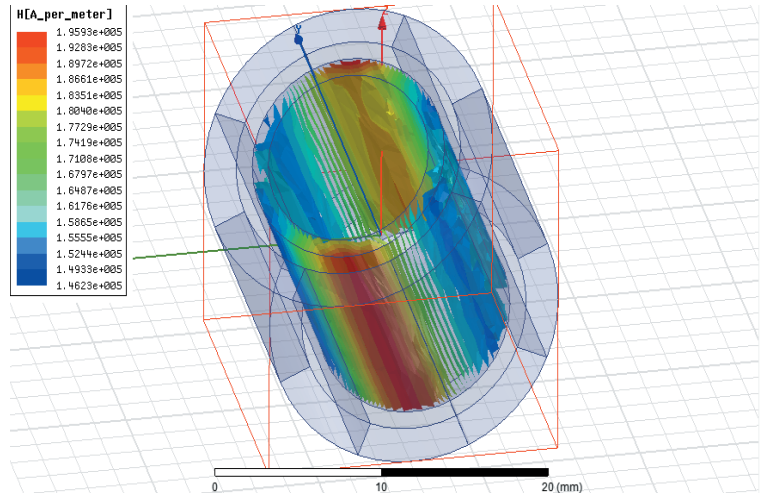

Figure 4. Magnet Field Strength Distribution for aluminium work piece

The above figure shows a magnet with eight pieces of an outer diameter of $36 \mathrm{~mm}$ diameter and an inner diameter of $32 \mathrm{~mm}$.theworkpiece is made up of a hollow tube of an outer diameter of $30 \mathrm{~mm}$, and a thickness of $5 \mathrm{~mm}$ was made. The material assign to the magnet is NDFE 35 and that of the workpiece is aluminium. The above figure shows the J's distribution on the aluminium with the maximum value of $40.064(\mathrm{~A} / \mathrm{m} 2)$ and the minimum value of 0.09635 $(\mathrm{A} / \mathrm{m} 2)$. Aluminium is non-ferrous material. With this simulation, it is evident that the magnetic field's intensity on the surface would be less than the ferrous material. The result would be almost similar to Brass as they both share the same non-ferrous material property.

The above figure shows a magnet with eight pieces of an outer diameter of $36 \mathrm{~mm}$ diameter and an inner diameter of $32 \mathrm{~mm}$.the workpiece is made up of a hollow tube of an outer diameter of $30 \mathrm{~mm}$. A thickness of $5 \mathrm{~mm}$ was made. The material assign to the magnet is NDFE 35 and that of the workpiece is aluminium. The above figure shows the H's distribution on the aluminium with the maximum value of $19593(\mathrm{~A} / \mathrm{m})$ and the minimum value of $14623(\mathrm{~A} / \mathrm{m})$. Aluminium is a non-ferrous material. With this simulation, it is evident that the magnetic field's intensity on the surface would be less compared to the ferrous material. The result would be almost similar to Brass as they both share the same non-ferrous material property.

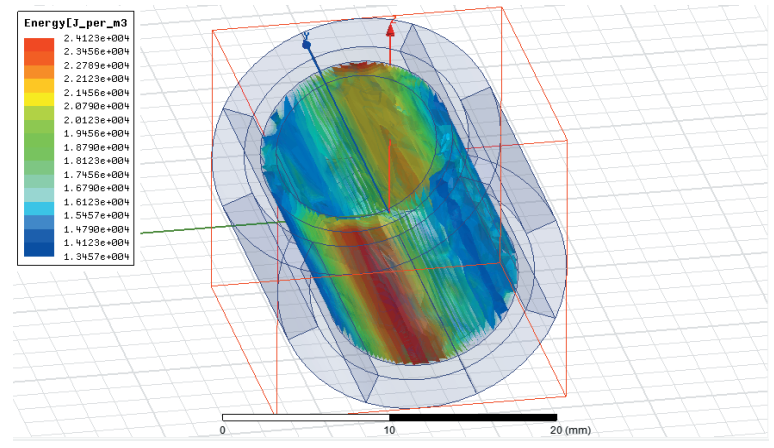

Figure 5. Energy Distribution for aluminium work piece

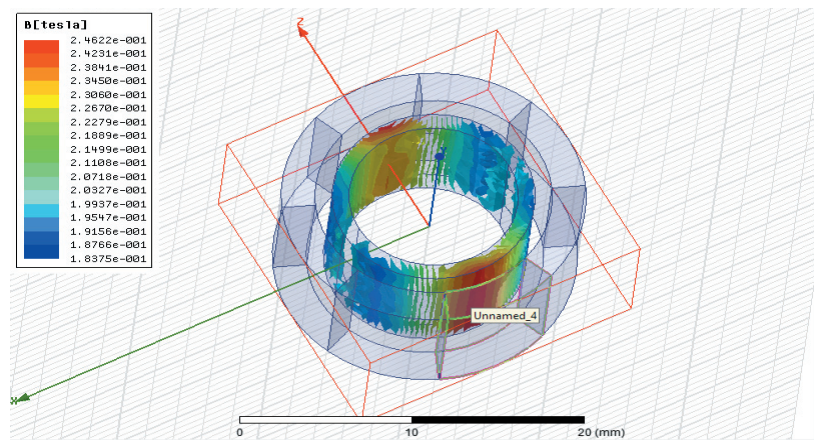

Figure 6. Magnetic field Distribution for Brass work piece 
The above figure shows a magnet with eight pieces of an outer diameter of $36 \mathrm{~mm}$ diameter and an inner diameter of $32 \mathrm{~mm}$. The workpiece is made up of a hollow tube of an outer diameter of $30 \mathrm{~mm}$. A thickness of $5 \mathrm{~mm}$ was made. The material assign to the magnet is NDFE 35 and that of the workpiece is aluminium. The above figure shows the aluminum's energy distribution with the maximum value of $24123(\mathrm{~J} / \mathrm{m} 3)$ and the minimum value of $13457(\mathrm{~J} /$ $\mathrm{m} 3$ ). Aluminium is a non-ferrous material. With this simulation, it is evident that the magnetic field's intensity on the surface would be less compared to the ferrous material. The result would be almost similar to Brass as they both share the same non-ferrous material property.

The above figure shows a magnet with eight pieces of an outer diameter of $36 \mathrm{~mm}$ diameter and an inner diameter of $32 \mathrm{~mm}$. The workpiece is made up of a hollow tube of an outer diameter of $30 \mathrm{~mm}$. A thickness of $5 \mathrm{~mm}$ was made. The material assign to the magnet is NDFE 35 and that of a workpiece is aluminium. The above figure shows the Magnetic Field's distribution on the Brass with the maximum value of 0.2462 Tesla and the minimum value of 0.18375 Tesla. Brass is a non-ferrous material. With this simulation, it is evident that the magnetic field's intensity on the surface would be less than the ferrous material. The result would be almost similar to Brass as they both share the same non-ferrous material property.

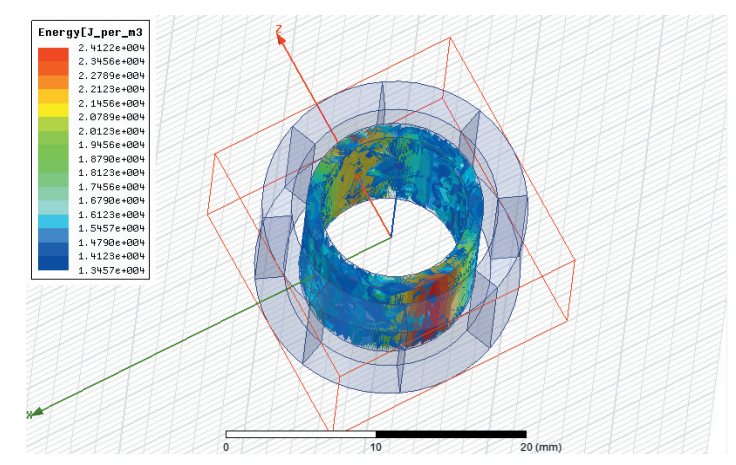

Figure 7. Energy Distribution for Brass work piece

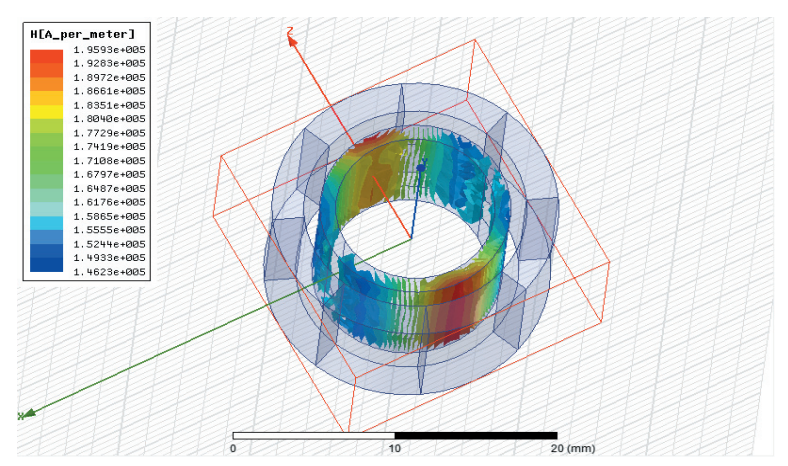

Figure 8. Magnetic Field Strength Distribution for Brass work piece

The above figure shows a magnet with eight pieces of an outer diameter of $36 \mathrm{~mm}$ diameter and an inner diameter of $32 \mathrm{~mm}$. The workpiece is made up of a hollow tube of an outer diameter of $30 \mathrm{~mm}$. A thickness of $5 \mathrm{~mm}$ was made. The material assign to a magnet is NDFE 35 and that of a workpiece is aluminium. The above figure shows the energy distribution on the Brass with the maximum value of $24122(\mathrm{~J} / \mathrm{m} 3)$ and the minimum value of $13457(\mathrm{~J} / \mathrm{m} 3)$. Brass is a non-ferrous material. With this simulation, it is evident that the magnetic field's intensity on the surface would be less compared to the ferrous material. The result would be almost similar to Brass as they both share the same non-ferrous material property.

The above figure shows a magnet with eight pieces of an outer diameter of $36 \mathrm{~mm}$ diameter and an inner diameter of $32 \mathrm{~mm}$. The workpiece is made up of a hollow tube of an outer diameter of $30 \mathrm{~mm}$. A thickness of $5 \mathrm{~mm}$ was made. The material assign to a magnet is NDFE 35 and that of a workpiece is aluminium. The above figure shows the H's distribution on the Brass with the maximum value of $19593(\mathrm{~A} / \mathrm{m})$ and the minimum value of $14623(\mathrm{~A} / \mathrm{m})$. Brass is a non-ferrous material. With this simulation, it is evident that the magnetic field's intensity on the surface would be less compared to the ferrous material. The result would be almost similar to Brass as they both share the same non-ferrous material property. 


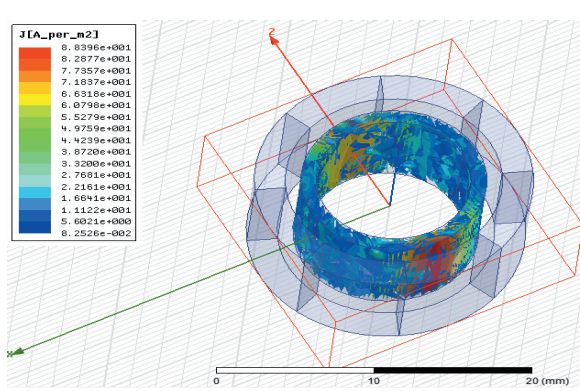

Figure 9. Current Density Distribution for Brass workpiece

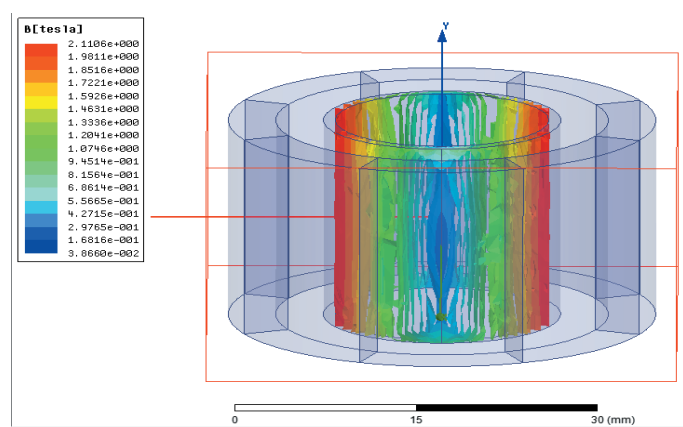

Figure 10. Magnetic Field Distribution for Steel work piece

The above figure shows a magnet with eight pieces of an outer diameter of $36 \mathrm{~mm}$ diameter and an inner diameter of $32 \mathrm{~mm}$. The workpiece is made up of a hollow tube of an outer diameter of $30 \mathrm{~mm}$. A thickness of $5 \mathrm{~mm}$ was made. The material assign to the magnet is NDFE 35 and that of the workpiece is aluminium. The above figure shows the $\mathrm{J}$ on the Brass's distribution with the maximum value of $88.396(\mathrm{~J} / \mathrm{m} 2)$ and the minimum value of $0.00825626(\mathrm{~J} / \mathrm{m} 2)$. Brass is a non-ferrous material. With this simulation, it is evident that the magnetic field's intensity on the surface would be less compared to the ferrous material. The result would be almost similar to Brass as they both share the same non-ferrous material property.

The above figure shows a magnet with eight pieces of an outer diameter of $36 \mathrm{~mm}$ diameter and an inner diameter of $32 \mathrm{~mm}$. The workpiece is made up of a hollow tube of an outer diameter of $30 \mathrm{~mm}$. A thickness of $5 \mathrm{~mm}$ was made. The material assign to the magnet is NDFE 35 and that of the workpiece is aluminium. The above figure shows the Magnetic Field's distribution on the Steel with the maximum value of 2.11 Tesla and the minimum value of 0.03886 Tesla. Steel and Steel's workpiece is a ferrous material that supports a larger magnetic field.

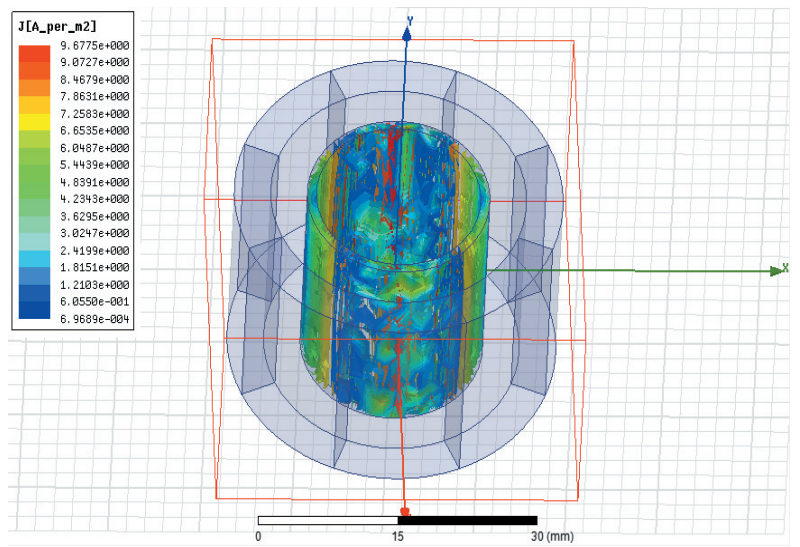

Figure 11. Current Density Distribution for Steel workpiece

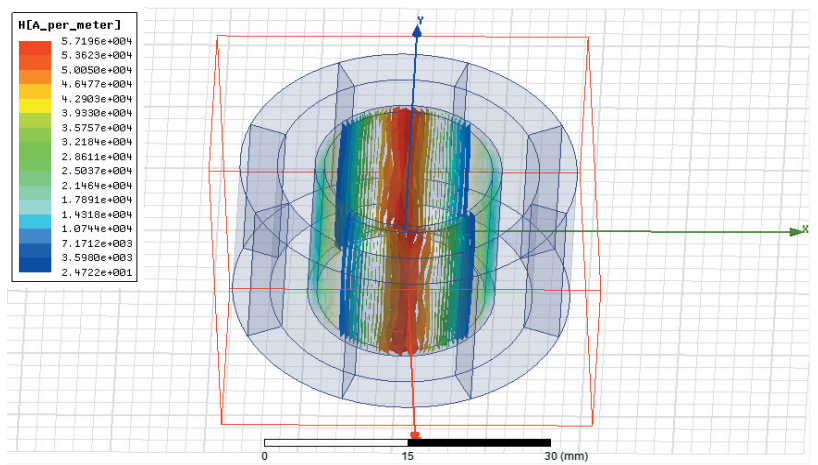

Figure 12. Magnet Field Strength Distribution for Steel workpiece 
The above figure shows a magnet with eight pieces of an outer diameter of $36 \mathrm{~mm}$ diameter and an inner diameter of $32 \mathrm{~mm}$. The workpiece is made up of a hollow tube of an outer diameter of $30 \mathrm{~mm}$. A thickness of $5 \mathrm{~mm}$ was made. The material assign to the magnet is NDFE 35 and that of the workpiece is aluminium. The above figure shows the $\mathrm{J}$ on the Steel's distribution with the maximum value of $9.67(\mathrm{~A} / \mathrm{m} 2)$ and the minimum value of $0.00069(\mathrm{~J} / \mathrm{m} 2)$. Steel and Steel's workpiece is a ferrous material that supports a larger magnetic field.

The above figure shows a magnet with an eight-piece of an outer diameter of $36 \mathrm{~mm}$ diameter and an inner diameter of $32 \mathrm{~mm}$. The workpiece is made up of a hollow tube of an outer diameter of $30 \mathrm{~mm}$ and a thickness of 5 $\mathrm{mm}$ was made. The material assign to a magnet is NDFE 35 and that of the workpiece is aluminium. The above figure shows the H on the Steel's distribution with the maximum value of $57196(\mathrm{~A} / \mathrm{m})$ and the minimum value of 24.722 $(\mathrm{J} / \mathrm{m})$. The workpiece is made up of Steel, and Steel is a ferrous material that supports a larger magnetic field.

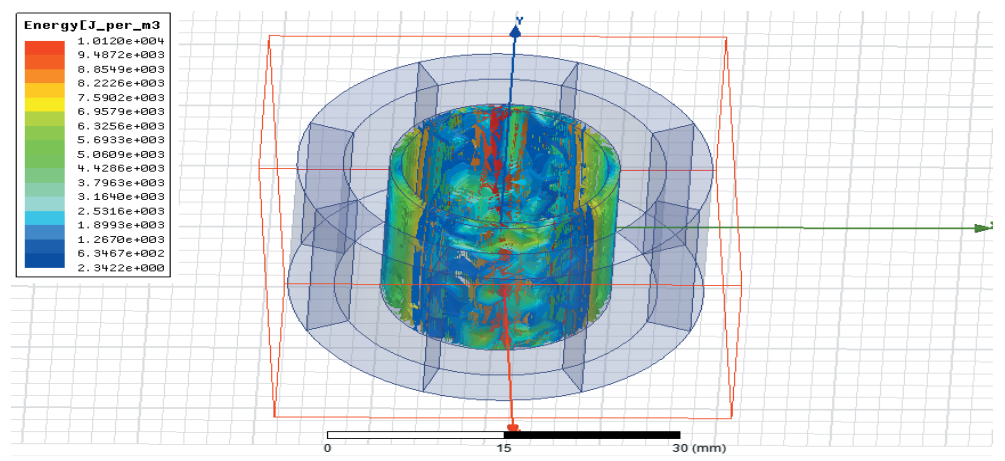

Figure 13. Energy Distribution for Steel workpiece

The above figure shows a magnet with eight pieces of an outer diameter of $36 \mathrm{~mm}$ diameter and an inner diameter of $32 \mathrm{~mm}$. The workpiece is made up of a hollow tube of an outer diameter of $30 \mathrm{~mm}$. A thickness of $5 \mathrm{~mm}$ was made. The material assign to a magnet is NDFE 35 and that of a workpiece is aluminium. The above figure shows Steel's energy distribution with the maximum value of $10120(\mathrm{~J} / \mathrm{m} 3)$ and the minimum value of $203422(\mathrm{~J} / \mathrm{m} 3)$. Brass is a non-ferrous material. With this simulation, it is evident that the magnetic field's intensity on the surface would be less compared to the ferrous material. The result would be almost similar to Brass as they both share the same non-ferrous material property.

\section{RESULTS AND DISCUSSION}

After the successful simulations on ANSYS MAXWELL, to compare the magnetic property produced by the wind turbine magnet on the internal gear made up of different material, The result obtained from simulations was tabulated. It was grouped into four sub-groups: Magnetic flux density, Magnetic field strength, current Density, and magnetic energy. Table 1 shows the values of magnetic flux density of Aluminium, Brass and Steel.

Table 1 Magnetic Flux Density of Aluminium, Brass and Steel

\begin{tabular}{|c|c|c|c|}
\hline Material & Maximum Value & Minimum Value & Average Value \\
\hline Aluminium & 0.2462 & 0.1837 & 0.21495 \\
\hline Brass & 0.246 & 0.1875 & 0.21675 \\
\hline Steel & 2.1106 & 0.0386 & 1.0746 \\
\hline
\end{tabular}


Figure 14 shows the Comparison of the Magnetic Flux Density of Aluminium, Brass and Steel in the graphical form, which was made using the above values.

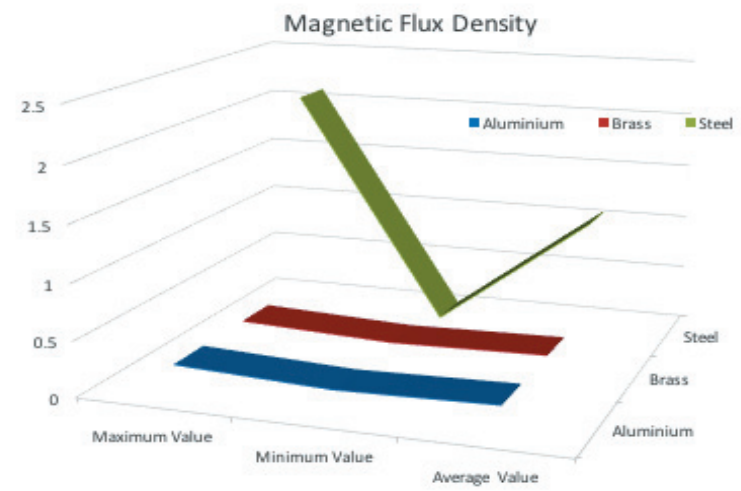

Figure 14 Comparison of the Magnetic Flux Density of Aluminium, Brass and Steel

It is evident that the value of magnetic flux density for the Steel is far better than the Brass and Aluminium as it is a ferromagnetic material and as the magnetic flux density increases, the effect of brush formation over the surface is more or, in another word the interaction of abrasive and surface rises which results in the effective machining process. Table 2 shows the value of Aluminium's Current Density, Brass and Steel obtained after the simulation.

Table 2 Comparison of Magnetic Flux Density of Aluminium, Brass and Steel

\begin{tabular}{|c|c|c|c|}
\hline Material & Maximum Value & Minimum Value & Average Value \\
\hline Aluminium & 4.0064 & 0.0963 & 2.05135 \\
\hline Brass & 8.8396 & 0.0825 & 4.46105 \\
\hline Steel & 9.6775 & 0.0069 & 4.8422 \\
\hline
\end{tabular}

Figure 15 shows the Comparison of the Magnetic Flux Density of Aluminium, Brass and Steel in the graphical form, which was made using the above values.

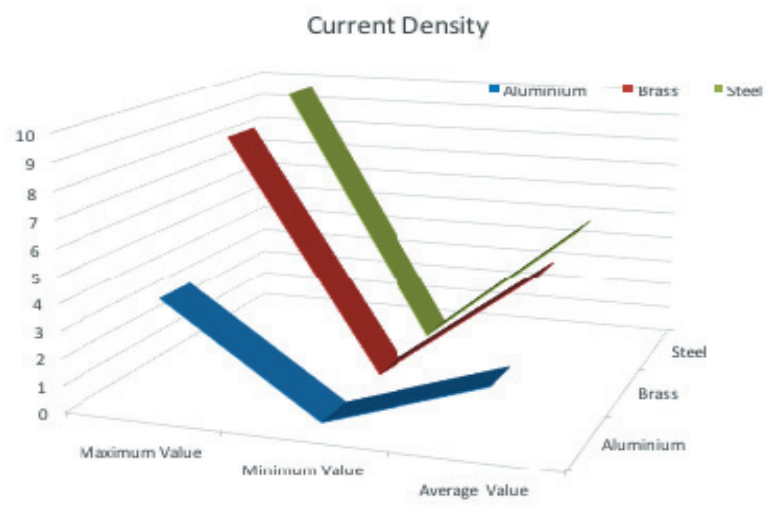

Figure 15 Comparison of the Current Density of Aluminium, Brass and Steel 
After comparing the values of current Density from the simulation, it is evident that aluminium possesses the lowest value of current Density, Then Brass and Steel have the highest value. Thus making Steel the eligible candidate for the machining when electromagnets are used. Table 3 shows the value of the Magnetic Field Strength of Aluminium, Brass and Steel obtained after the simulation.

Table 3. Magnetic Field Strength of Aluminium, Brass and Steel

\begin{tabular}{|c|c|c|c|}
\hline Material & Maximum Value & Minimum Value & Average Value \\
\hline Aluminium & 19539 & 14263 & 16901 \\
\hline Brass & 19593 & 14632 & 17112.5 \\
\hline Steel & 57196 & 2.4722 & 28599.2361 \\
\hline
\end{tabular}

Figure 16 shows the Comparison of the Magnetic Field Strength of Aluminium, Brass and Steel in the graphical form, which was made using the above values.

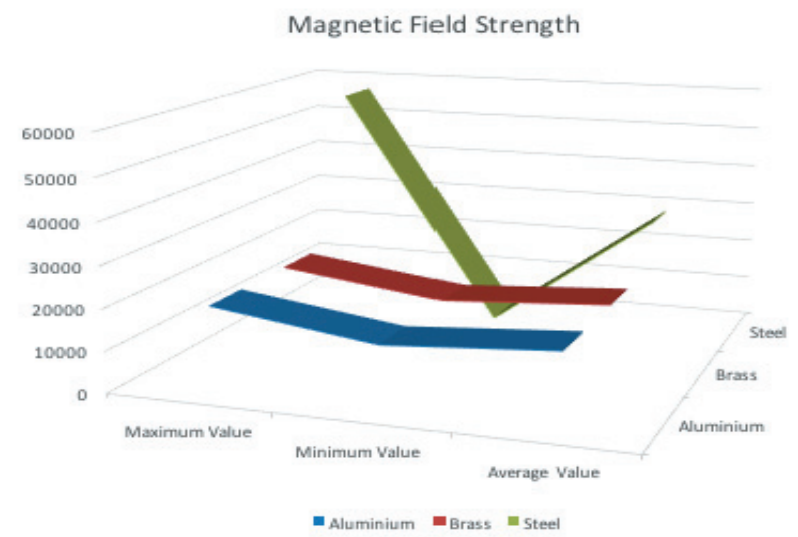

Figure 16. Comparison of the Magnetic Feild Strength of Aluminium, Brass and Steel

After comparing the Magnetic Feild Strength values from the simulation, it is evident that Brass possesses the highest value of Magnetic Feild Strength, followed by aluminium and Steel have the most negligible value. Thus making Brass the eligible candidate for the machining when electromagnets and Permanent Magnet are used. Table 4 shows the value of the Magnetic Energy of Aluminium, Brass and Steel obtained after the simulation.

Table 4. Magnetic Energy of Aluminium, Brass and Steel

\begin{tabular}{|c|c|c|c|}
\hline Material & Maximum Value & Minimum Value & Average Value \\
\hline Aluminium & 24132 & 13475 & 18803.5 \\
\hline Brass & 24122 & 13457 & 18789.5 \\
\hline Steel & 10120 & 2.3422 & 5061.1711 \\
\hline
\end{tabular}




\section{CONCLUSION}

After going through the simulations and the graphs, the researchers made the following conclusions firstly Viscoelastic Magnetic Abrasive finishing Process is the most prominent method for finishing internal gears. From this investigation it can be concluded that ANSYS MAXWELL is one of the efficient tools for Magnetic based simulations. The Wind Turbine magnet of $36 \mathrm{~mm}$ Outer Diameter magnet is most suitable for viscoelastic magnetic abrasive Finishing than the other commercially available magnet. It can be observed that when the above magnet is used, the distribution of the field is maximum, making it suitable for the MAF process. In terms of magnetic flux density, Steel's workpiece has the edge over the other two materials. Brass has the edge over the other two materials in terms of magnetic field strength and magnetic energy. In terms of current Density, Steel leads the other two materials.

\section{REFERENCES}

Wnag, Y., Hu, D.J. 2004. Mechanical Cutting Model of Magnetic Abrasive Particles and Analysis of experimental Results. DOI 10.4028/Scientific.net/KEM.274-276.451.

Rampal, Rohit., Goyal, Tarun. 2017. Comparing the techniques for Magnetic Abrasives by Investigating the Surface Finish IJAER, ISSN 0973-4562 Volume 12, Number 19 pp.8972-8975.

Kang, Paramvir.Singh., Singal, L.C., Gill, Rajwinder. Singh. 2017. Effectiveness of sintered Abrasive in Magnetic Abrasive Finishing. IJAMTE, ISSN NO: 2249-7455.

Muhamad, M.R., Zou, Y., Sugiyama, H. 2016. Investigation of the finishing characteristics in an internal tube finishing process by magnetic abrasive finishing combined with electrolysis, Taylor and Francis, DOI 10.1080/00202967.2016.1162400.

Shrikhande, Nikhil. S., Deshkar, Amey. A., Awasthi, Saurabh. S., Meshram, Akshay V., Dhoble, P. Ashwini., Jumle, Patric. A., Kapgate, Bhubneshwar. M. 2018. Magnetic Field assisted Abrasive Flow machine-based Surface Super Finishing, (IJRASET), 6(4).

Chen, H.L., Li, W.H., Yang, S. Q., Yang, S.C. 2010. Research of Magnetic Abrasive Prepared by hot Pressing sintering process, IEEE 978-1-4244-5046-6.

Judal, K.B., (2016) FEM Based Modelling of Cylindrical Magnetic Abrasive Finishing (C-MAF) Process using unbounded Magnetic Abrasives, Asia Pacific Journal, ISBN 978-81-930411-8-5.

Srinivas, K., Murtaza, Q., Aggarwal, A.K. 2019. Effect of Shape of Magnet on the Machining of Workpiece, International Journal of Recent Technology and Engineering (IJRTE), ISSN: 2277-3878, 8(2): 2011 .

Srinivas, K., Murtaza, Q., Aggarwal, A.K. 2019. effect of permanent magnetic pole orientation on-field strength in viscoelastic magnetic abrasive finishing process International Journal of Mechanical and Production Engineering Research and Development. 9, Issue 5, Oct 2019, 43-52.

Srinivas, K., Murtaza, Q., Aggarwal, A.K. 2019. Modelling Of Viscoelastic Fluid In Finishing Processes. International journal of scientific \& technology research. 8(9).

Srinivas, K., Murtaza, Q., Aggarwal, A.K. 2019. Variation of flow parameters and Magnetic flux in Viscoelastic Magnetic Abrasive Finishing Process, International Journal of Applied Engineering Research. 14(8): 1940-1946. 